\title{
AVALIAÇÃO DA ABORDAGEM DOS CONTEÚDOS DE ALIMENTAÇÃO E NUTRIÇÃO NO LIVRO DE CIÊNCIAS DA \&A SÉRIE UTILIZADO NO MUNICÍPIO DE PETROLINA-PE
}

\author{
Diego Felipe dos Santos Silva ${ }^{1}$ \\ Rosane Nunes Garcia²
}

\begin{abstract}
RESUMO
O presente trabalho trata da análise dos livros didáticos utilizados para o ensino de Ciências nos anos finais do Ensino Fundamental adotados pelas escolas públicas do município de Petrolina-PE, a fim de verificar como é a abordagem do tema Alimentação e Nutrição nesse material. A metodologia utilizada foi a análise documental, realizada a partir de dois critérios: 1 - conceitos considerados essenciais ao entendimento e à prática da alimentação saudável; e 2 - questões que podem motivar os indivíduos a modificarem suas práticas alimentares. Identificou-se que dos quatro livros analisados apenas um apresentou conteúdos relacionados à temática. Com relação aos conteúdos de relevante importância para o entendimento e a prática da alimentação saudável, verificou-se que todos são apresentados nos livros, com exceção da diversidade alimentar e a classificação dos alimentos. Sobre os conteúdos que podem motivar os indivíduos a modificarem suas práticas alimentares, é importante destacar que a causa ou origem da doença, bem como a perspectiva de orientação nutricional é ausente em todos os capítulos. Embora o livro didático seja uma fonte de informação e de divulgação do conhecimento científico muito utilizada pelos estudantes, a abordagem apresentada nos livros didáticos pesquisados foi limitada em diversos momentos, exposta de forma superficial e não apresentou aspectos essenciais sobre a temática da Alimentação e Nutrição.
\end{abstract}

Palavras-chave: Educação Básica. Educação alimentar. Ensino de Ciências.

\section{EVALUATION OF THE APPROACH TO FOOD AND NUTRITION CONTENTS IN THE SCIENCE BOOK OF THE 8TH SERIES USED IN THE MUNICIPALITY OF PETROLINA-PE}

\begin{abstract}
The present work deals with the analysis of textbooks used for teaching science in the final years of elementary school, adopted by the public schools of the municipality of Petrolina-PE, in order to verify how is the approach of the theme Food and Nutrition in this material. The methodology used was documental analysis, based on two criteria: 1 - concepts considered essential to understanding and practicing healthy eating; and 2 -issues that may motivate individuals to change their eating practices. We identified that of the four books analyzed, only one presented content related to the theme. We identified that of the four books analyzed, only one presented content related to the theme. With regard to the contents of relevant importance for the understanding and practice of healthy eating, it was verified that all are presented in the books, with the exception of food diversity and food classification. Regarding the contents that may motivate individuals to modify their eating practices, it is important to highlight that the cause or origin of the disease, as well as the perspective of nutritional orientation, is absent in all chapters. Although the textbook is a source of information and dissemination of scientific knowledge widely used by students, the approach presented in the textbooks researched was limited in several moments, exposed superficially and did not present essential aspects on the subject of Food and Nutrition.
\end{abstract}

Keywords: Basic Education. Nutrition education. Science teaching.

RECEBIDO EM: 7/3/2018

ACEITO EM: 2/1/2020

\footnotetext{
1 Autor correspondente. Universidade de Pernambuco (UPE) - Campus Petrolina. Rodovia BR 203, Km 2, s/n - Vila Eduardo. CEP 56328-900. Petrolina/PE, Brasil. http://lattes.cnpq.br/6060534833080549. https://orcid.org/0000-0003-3105-1428. diego.santos@upe.br

2 Universidade Federal do Rio Grande do Sul - UFRGS. Porto Alegre/RS, Brasil. http://lattes.cnpq.br/5287986618410207. https://orcid. org/0000-0002-4647-6245
} 
Do ponto de vista da saúde, a fase escolar é essencial para o desenvolvimento de conhecimentos e práticas de autocuidado (PICCOLI; JOHANN; CORRÊA, 2010). A atribuição da escola é direcionada para a construção do desenvolvimento crítico dos alunos, no intuito de formá-los para se tornarem cidadãos conscientes. Nesse sentido, as atividades educativas que ocorrem no âmbito escolar necessitam constituir ou incorporar inúmeras táticas/recursos pedagógicos que possibilitem ao aluno tornar-se ativo no processo de ensino-aprendizagem, promovendo debates, discussões, problematização e reflexão sobre os resultados de suas decisões, tanto individualmente quanto no meio social (CATRIB et al., 2003). Dessa forma, "tanto os setores da educação quanto da saúde cooperam para o desenvolvimento de capacidades, aquisições e competências individuais e coletivas com foco direcionado a construir hábitos saudáveis" (ILHA et al., 2013).

Nessa perspectiva, percebe-se uma grande preocupação com os hábitos alimentares desde a infância, pelo fato de tais hábitos estarem associados a diversos problemas de saúde de forma aguda ou crônica (a exemplo das doenças cardiovasculares e a obesidade), posto que a falta de conhecimento pode contribuir para o aumento do risco e o desenvolvimento de tais doenças (PERES et al., 2018). Esse acontecimento colabora, de modo crescente, para a conscientização da sociedade com vistas a minimizar ou evitar tais problemas (SCHMITZ et al., 2008). Por essa razão, considera-se que o ensino sobre Alimentação e Nutrição se torna fundamental para promover saúde e precisa ter relevância no ambiente escolar, fazendo parte de um plano nacional e oficial de ensino, conforme afirmam Bizzo e Leder (2005), amparados pelo parecer que institui as Diretrizes Curriculares Nacionais para o Ensino Fundamental (BRASIL, 1998b).

Dentro do âmbito da educação básica no Brasil existem as Diretrizes Curriculares Nacionais (DCNs), que constituem o plano curricular nacional e oficial para o ensino fundamental. Trata-se de um conjunto de definições doutrinárias sobre princípios, fundamentos e procedimentos na Educação Básica, expressas pela Câmara de Educação Básica do Conselho Nacional de Educação que orienta as escolas brasileiras do sistema de ensino, na organização, na articulação, no desenvolvimento e na avaliação de suas propostas pedagógicas (BRASIL, 1998). Além das disciplinas tradicionais, abrangem mais seis temas transversais: ética, pluralidade cultural, meio ambiente, saúde, orientação sexual, trabalho e consumo (BIZZO; LEDER, 2005, p. 662).

As DCNs para o Ensino Fundamental ditam que sejam tratadas, na escola, questões relacionadas à saúde, principalmente por essa ser fator determinante na evolução da existência humana. O fato, contudo, é que esse tema é colocado de modo mais generalizado, sem haver um aprofundamento nas abordagens sobre saúde e sem definir quais conteúdos relacionados à Alimentação e Nutrição podem ser ensinados no Ensino Fundamental (REBOUÇAS, 2013). A educação escolar poderia colaborar bastante com o desenvolvimento e o entendimento de temas relacionados à saúde, uma vez que uma das incumbências da escola é o de propagar conhecimento cientifico, além de promover a formação para a cidadania (MACHADO; DE CARVALHO, 2015). Nesse contexto, a escola, por meio de propostas transformadoras de ensino, tem um papel fundamental e de relevância em relação ao cuidado integral à saúde dos estudantes e na propagação da promoção desta (PERES et al., 2018). 
Nessa lógica, os Parâmetros Curriculares Nacionais para o Ensino Fundamental (BRASIL, 1998a) destacam a relevância em empregar diferentes recursos didáticos no processo de ensino e de aprendizagem. Sobre tais recursos, dentre os diversos instrumentos que podem ser utilizados destaca-se o livro didático, que representa uma das ferramentas de grande influência na prática de ensino (BARATA; BARRETO, 2013), sendo apontado como um dos principais recursos de apoio acadêmico em virtude da sua função em auxiliar como reforço/apoio didático, tanto teórico quanto prático, para o professor e para o estudante (BRASIL, 2003; TEIXEIRA; SIGULEM; CORREIA, 2011).

No que se refere ao âmbito educacional, é perceptível que a escola se apresenta organizada de modo a possuir uma relação estreita com o uso do livro didático, tornando-se evidente, em inúmeras situações, que esse seja o principal instrumento organizador para o trabalho na sala de aula (FREITAS; MARTINS, 2008).

Por se tratar de uma temática que possibilita diversas abordagens, os livros didáticos, seja pelos conteúdos e temas abordados, pela forma e lógica de desenvolvimento das atividades propostas, podem expressar diferentes concepções de promoção da saúde e diferentes compreensões e construções do processo saúde-doença. Podem também, expressar entendimentos diversos acerca dos fatores determinantes e condicionantes para promover a qualidade de vida (ILHA et al., 2013, p. 108).

Cardoso e Moreira (2016), ao pesquisarem sobre os livros didáticos do Ensino Fundamental e sua relação aos conteúdos referentes à alimentação e nutrição, identificaram que existe uma reprodução da alimentação abordada, de modo convencional, por meio de conceitos e definições que visam apenas a atender aspectos disciplinares, apontando pouco espaço às reflexões sobre hábitos alimentares, aspectos culturais, entre outros. Ainda, segundo os autores, os livros analisados traziam uma abordagem sobre a temática "Alimentação e Nutrição" que se distanciava da concepção de promoção à saúde.

Pipitone et al. (2003), em pesquisa sobre a educação nutricional no Programa de Ciências para o Ensino Fundamental em escolas públicas de Piracicaba (SP), discutem que o tema Alimentação e Nutrição deveria apresentar maior destaque entre os conteúdos destinados para o Ensino Fundamental por meio da disciplina Ciências. A pesquisa mostrou, ainda, que, predominantemente, os professores seguem o livro didático, preconizando a compreensão da nutrição e da alimentação pelo panorama exclusivo da biologia, além de mencionar que os conteúdos eram, quase sempre, repetitivos, não possibilitando mudanças de hábitos.

Dessa forma, fica evidenciado que é importante que seja realizada uma análise dos conteúdos contidos nos livros didáticos utilizados no município de Petrolina-PE, a fim de que possa ser concretizada uma avaliação sobre temas fundamentais para o aprendizado na educação básica, como é o caso da Alimentação e Nutrição. Por esse ângulo, o presente estudo tem como objetivo identificar e analisar a temática relacionada à Alimentação e Nutrição contida no livro didático utilizado nos anos finais do Ensino Fundamental, a fim de verificar em que precisa ser modificada e, posteriormente, auxiliar o trabalho do professor na mediação das informações apresentadas. 


\section{METODOLOGIA}

Trata-se de pesquisa documental referente ao material didático (livros) utilizado nos anos finais do Ensino Fundamental das escolas públicas do município de Petrolina-PE, realizada durante os meses de março a dezembro de 2015.

A partir da visita e apresentação da pesquisa à Secretaria Municipal de Educação de Petrolina-PE, foi possível ter acesso ao livro didático utilizado pelos professores de Ciências do município referente ao Ensino Fundamental (anos finais), e obter os descritores de ciências do município que indicam os conteúdos que devem ser ministrados pelos professores durante o ano letivo. Esses descritores estão classificados de acordo com os quatro bimestres letivos e por ano (Bimestre I - Valores Humanos; Bimestre II Saúde e Qualidade de Vida; Bimestre III - Sustentabilidade de Desenvolvimento; Bimestre IV - O mundo tecnológico).

Os livros didáticos escolhidos para análise consistiram em exemplares utilizados na disciplina Ciências no Ensino Fundamental (pertencentes ao Programa Nacional do Livro Didático - PNLD, correspondente ao triênio 2014, 2015 e 2016), adotados (de modo único) por todas as escolas da rede municipal de educação da cidade de Petrolina-PE no ano de 2015. Teve-se acesso a um exemplar de cada volume, correspondente a cada série, fornecido em forma de empréstimo pela Secretaria de Educação (Seduc) de Petrolina.

Os livros analisados (6ำ ao 9 ano) são do Projeto Araribá Ciências (3ạ edição), publicados no ano de 2010, organizados pela Editora Moderna, e possuem como editora responsável Vanessa Shimabukuro. Nesta coleção, as Ciências da Natureza (Química, Física e Biologia) estão apresentadas em correspondência ao componente curricular único de Ciências, em conformidade com a legislação nacional para os anos finais do Ensino Fundamental da Educação Básica. Esse material didático tem por finalidade atender estudantes na faixa etária entre 11 e 14 anos de idade.

Para a realização das análises dos livros, tomou-se por base a pesquisa realizada por Teixeira, Sigulem e Correia (2011) e adotaram-se os critérios utilizados no referido estudo, de forma adaptada (usando-se, também, critérios abordados no Guia Alimentar para a População Brasileira), como instrumento de coleta de dados. É importante ressaltar que os critérios destacados são fundamentais para a obtenção de informações satisfatórias que promovam práticas alimentares saudáveis, conforme segue a seguir, divididas em dois grupos:

Critério 1 - conceitos considerados essenciais ao entendimento e à prática da alimentação saudável (carboidratos, proteínas, gorduras, vitaminas, minerais, água, fibras, pirâmide dos alimentos, diversidade alimentar/cultura alimentar, alimentos in natura, alimentos processados e alimentos ultraprocessados);

Critério 2 - questões que podem motivar os indivíduos a modificarem suas práticas alimentares (doenças cardiovasculares, diabetes, obesidade, anemia ferropriva, transtornos alimentares, influência da mídia na alimentação).

Para a realização da análise, no que se refere à relevância dos critérios 1 e 2, foram organizadas três categorias de avaliação dos itens: "suficiente", "insuficiente" e "ausente", definidas da seguinte forma: Suficiente (variáveis analisadas presentes nos 
livros didáticos e em concordância com os conhecimentos atuais); Insuficiente (variáveis parcialmente presentes nos livros didáticos, em concordância com os conhecimentos atuais) e Ausente (conteúdo não foi abordado no livro didático). Conteúdos presentes, porém desatualizados ou incorretos, foram analisados individualmente e de forma descritiva (TEIXEIRA; SIGULEM; CORREIA, 2011).

\section{RESULTADOS}

Foram analisados quatro livros didáticos da disciplina Ciências, sendo possível identificar que, destes, apenas um apresentou conteúdos relacionados à temática pesquisada.

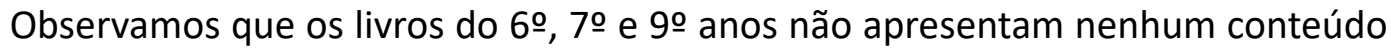
sobre o tema estudado. Assim, pode-se observar que apenas o livro do 8o ano abordou/ apresentou conteúdo sobre Alimentação e Nutrição e, nessa perspectiva, deteve-se no mesmo para realizar as análises que seguem.

O livro apresenta os conteúdos dispostos por unidades temáticas, totalizando oito unidades no decorrer de todo o livro, e cada unidade apresenta, em média, de 6 a 10 temas. Observa-se que o tema 1, em todas as unidades, sempre é intitulado "De olho nas notícias", que traz textos de livros, revistas, pesquisas ou matérias jornalísticas sobre o tema.

A unidade que aborda a temática pesquisada neste estudo (Alimentação e Nutrição) é vista na unidade 6 (intitulada "Bom Apetite!") do livro do 8o ano do Ensino Fundamental. Está disposto da seguinte forma: Tema 1 - De olho nas notícias (aborda duas reportagens de pesquisas científicas que envolvem o uso de açúcar simples e a outra sobre a dieta do brasileiro que consome excesso de calorias); Tema 2 -A nutrição e os alimentos; Tema 3 - Vitaminas e sais minerais; Tema 4 - Carboidratos, Lipídios e Proteínas; Tema 5 - A energia dos alimentos (as calorias); Tema 6 - A dieta adequada; Tema 7 - A nutrição: o sistema digestório; Tema 8 - As etapas da digestão (I); Tema 9 - As etapas da digestão (II); Tema 10 - A saúde do sistema digestório.

A análise referente aos critérios 1 que abrangem os conteúdos de relevante importância para o entendimento e a prática da alimentação saudável (Quadro 1), evidencia que todos os conteúdos são apresentados no livro, com exceção da diversidade alimentar e da classificação dos alimentos. Já a abordagem química dos conteúdos, apenas naqueles relacionados a Carboidratos e Proteínas, trata deste foco. O livro não expõe nenhum detalhamento sobre a importância da ingestão de água e do consumo de fibras para a alimentação adequada, além da evidência clara da insuficiência na abordagem sobre a relevância do conteúdo apresentado. 
Quadro 1 - Análise do livro do 8o ano de Ciências, para as variáveis 1, quanto à presença ou ausência dos conteúdos para o entendimento e a prática da alimentação saudável. Petrolina-PE, 2016

\begin{tabular}{|c|c|c|c|c|c|c|c|}
\hline Conteúdo & $\begin{array}{l}\text { Presença ou } \\
\text { Ausência do } \\
\text { tema }\end{array}$ & $\begin{array}{l}\text { Química/ } \\
\text { Bioquímica }\end{array}$ & $\begin{array}{l}\text { Consumo } \\
\text { diário }\end{array}$ & $\begin{array}{c}\text { Fontes } \\
\text { alimentares }\end{array}$ & Funções & $\begin{array}{c}\text { Relevância } \\
\text { do } \\
\text { conteúdo }\end{array}$ & Observações \\
\hline Carboidratos & $P$ & $P$ & $P$ & $P$ & $P$ & 1 & - \\
\hline Proteínas & $\mathrm{P}$ & $\mathrm{P}$ & $\mathrm{P}$ & $\mathrm{P}$ & $\mathrm{P}$ & 1 & - \\
\hline Gorduras & $\mathrm{P}$ & A & $\mathrm{P}$ & $\mathrm{P}$ & $\mathrm{P}$ & 1 & - \\
\hline Vitaminas & $\mathrm{P}$ & A & $\mathrm{P}$ & $\mathrm{P}$ & $\mathrm{P}$ & 1 & - \\
\hline Minerais & $\mathrm{P}$ & $\mathrm{A}$ & $\mathrm{P}$ & $\mathrm{P}$ & $\mathrm{P}$ & 1 & - \\
\hline Água & $\mathrm{P}$ & A & A & A & A & $I^{*}$ & $\begin{array}{l}\text { A única } \\
\text { menção à } \\
\text { água é em } \\
\text { razão da sua } \\
\text { presença em } \\
75 \% \text { do corpo } \\
\text { humano }\end{array}$ \\
\hline Fibras & $\mathrm{P}$ & A & A & $A$ & A & 1 & - \\
\hline $\begin{array}{l}\text { Pirâmide dos } \\
\text { Alimentos }\end{array}$ & $\mathrm{P}$ & NSA & $\mathrm{P}$ & $\mathrm{P}$ & $\mathrm{P}$ & 1 & - \\
\hline $\begin{array}{l}\text { Diversidade } \\
\text { alimentar }\end{array}$ & A & A & A & A & A & 1 & - \\
\hline $\begin{array}{l}\text { Alimentos in } \\
\text { natura }\end{array}$ & A & A & A & A & A & 1 & - \\
\hline $\begin{array}{c}\text { Alimentos } \\
\text { processados }\end{array}$ & A & A & A & $A$ & A & 1 & - \\
\hline $\begin{array}{c}\text { Alimentos } \\
\text { ultraprocessados }\end{array}$ & A & A & A & A & A & 1 & - \\
\hline
\end{tabular}

Legenda: P - Presente; A - Ausente; NSA - Não se aplica; I - Insuficiente; *Muito insuficiente.

Fonte: Os autores.

Sobre os conteúdos que podem motivar os indivíduos a modificarem suas práticas alimentares (Quadro 2), é importante destacar que a causa ou origem da doença, bem como a abordagem relacionada à orientação nutricional, é ausente em todos os conteúdos, fato este que promove grande preocupação, tendo em vista a indispensabilidade em tratar sobre tais assuntos, que se apresentam insuficientes e sem a relevância necessária.

Quadro 2 - Análise do livro do 8o ano de Ciências, para as variáveis 2, quanto à presença ou ausência dos conteúdos para promover a mudança de práticas alimentares. Petrolina-PE, 2016

\begin{tabular}{|c|c|c|c|c|c|c|}
\hline Conteúdo & Presença & $\begin{array}{c}\text { Causa ou } \\
\text { origem }\end{array}$ & $\begin{array}{l}\text { Orientação } \\
\text { nutricional }\end{array}$ & Relevância & $\begin{array}{l}\text { Apresentação } \\
\text { do tema }\end{array}$ & Observações \\
\hline $\begin{array}{c}\text { Doenças } \\
\text { cardiovasculares }\end{array}$ & $P$ & A & A & I & I & $\begin{array}{l}\text { Apenas cita } \\
\text { a obesidade, } \\
\text { HAS e doenças } \\
\text { cardiovasculares } \\
\text { como consequências } \\
\text { de uma alimentação } \\
\text { rica em lipídios } \\
\text { (unidade 4) }\end{array}$ \\
\hline Diabetes & $\mathrm{P}$ & A & A & 1 & 1 & - \\
\hline Obesidade & $\mathrm{P}$ & A & A & $\mathrm{I}$ & I & - \\
\hline Anemia Ferropriva & $\mathrm{P}$ & A & A & 1 & 1 & - \\
\hline $\begin{array}{l}\text { Transtornos } \\
\text { alimentares }\end{array}$ & A & A & A & I & I & $=$ \\
\hline $\begin{array}{l}\text { Influência da } \\
\text { mídia }\end{array}$ & A & A & A & I & 1 & $=$ \\
\hline
\end{tabular}

Legenda: P - Presente; A - Ausente; I - Insuficiente; HAS - Hipertensão Arterial Sistêmica.

Fonte: Os autores. 


\section{Rousta \\ \&Educaçẵo}

Avaliação da Abordagem dos Conteúdos de Alimentação e Nutrição no Livro de Ciências

\section{DISCUSSÃO}

Ressalta-se que apenas o livro do 8 o ano da coleção avaliada abordava a temática pesquisada, o que, de certo modo, corrobora a pesquisa realizada por llha et al. (2013), que, em seu estudo, observa que, de forma geral, o tema promoção da saúde é desenvolvido praticamente somente no livro do 80 ano, estando esse ligado a conceituações e explicações informativas e não explorando o cotidiano dos alunos.

O mesmo fato pode ser identificado, também, na afirmação de Cardoso e Moreira (2016), que, dentre os livros do Ensino Fundamental II, fizeram um recorte de análise do livro didático do 8o ano, uma vez que é nesse nível escolar, que, tradicionalmente, ensina-se a temática da alimentação na disciplina Ciências.

Constata-se, atualmente, que o ambiente escolar se torna eficiente para se combaterem distúrbios alimentares, caso este seja um espaço onde problemas nutricionais sejam discutidos (SANTOS, 2005). Nesse sentido, é imprescindível, para minimizar tais problemas, a inserção da educação alimentar inserida na disciplina Ciências, que tem por finalidade

Possibilitar ao ser humano assumir com plena consciência a responsabilidade pelos seus atos relacionados à alimentação. A educação nutricional não é uma ferramenta mágica para levar o educando a obedecer à dieta, pelo contrário ela deve ser conscientizadora e libertadora, por isso deve buscar justamente o oposto: a autonomia do educando (BOOG, 1997, p. 17).

Segundo Ipiranga (1995), o Ensino Fundamental é, incontestavelmente, um excelente espaço social para desenvolver a compreensão dos alunos sobre suas escolhas quanto ao consumo de alimentos e a sua relação com a saúde e o bem-estar. Pode-se afirmar que a educação nutricional é uma ferramenta pertinente no ensino de Ciências, pois faz com que os conhecimentos sobre alimentação e nutrição sejam dialogados com os alunos, sendo o livro didático um instrumento importante para a conquista desse objetivo.

Nessa perspectiva, ao tratar sobre conteúdos de relevante importância para o entendimento e a prática da alimentação saudável (Quadro 1), observou-se que 8 das 12 variáveis/conteúdos estão presentes no livro. Os quatro conteúdos que não foram abordados não são nem ao menos citados ao longo do capítulo, o que evidencia um destaque desfavorável, principalmente por serem palavras-chaves (alimentos in natura, processados e ultraprocessados) utilizadas, atualmente, quando se fala em alimentação e estão apresentadas detalhadas no guia alimentar para a população brasileira (BRASIL, 2014).

Segundo Cardoso e Moreira (2016), a abordagem dos nutrientes é de extrema importância para a compreensão de problemas causados por uma alimentação inadequada tal como a de uso de alimentos processados e ultraprocessados. $O$ fato de os livros concentrarem a discussão no texto principal, no entanto, não garante essa reflexão. 
Concorda-se com Cardoso e Moreira (2016), pois observamos uma abordagem muito básica sobre os alimentos e os nutrientes, definindo-os de modo pontual e sem trazer nenhuma informação em âmbito de citação e muito menos que conduza os estudantes a refletirem sobre o assunto, de forma especial os alimentos, posto que apresentam uma grande relevância para a promoção da alimentação saudável.

Também fica claro que a forma pontual como o livro expõe os conteúdos faz com que inúmeros assuntos, que seriam pertinentes para conduzir uma reflexão e tornar o aluno mais presente na realidade alimentar brasileira, não são apresentados, a exemplo das questões envolvendo a diversidade alimentar e o respeito à cultura alimentar de cada região. A importância de se destacar esse conteúdo é no sentido de mostrar ao estudante a variedade alimentar existente no território nacional e a influência que o país sofre com a introdução de diversas novas culturas alimentares em nosso cotidiano, sejam de origem americana, japonesa, chinesa, chilena, mexicana ou italiana, e como tais influências acabam por determinar os hábitos alimentares da população.

Dessa forma, a construção de metodologias ou de materiais didáticos que aproximem o estudante à diversidade alimentar existente no Brasil e como se comporta cada região em relação aos hábitos alimentares, com suas particularidades e especificidades, conforme pode ser observado no atual Guia Alimentar para a População Brasileira (BRASIL, 2014), pode ser uma forma interessante de superar as dificuldades em torno do ensino a respeito da temática alimentação e nutrição na escola.

Destaca-se a pouca importância que é direcionada à ingestão de água e ao consumo de fibras, o que é indispensável na alimentação para a promoção da melhor qualidade de vida, principalmente pelo fato de a água ser essencial para a vida e para a regulação do organismo (homeostase celular, transporte de nutrientes e eliminação de substâncias tóxicas), além de que, associada ao consumo de fibras, melhora o funcionamento gastrointestinal, evitando constipações intestinais (HAAS; ANTON; FRANCISCO, 2007). As fibras também desempenham funções importantes no controle das doenças cardiovasculares e diabetes tipo 2 (RIQUE; SOARES; MEIRELLES, 2002), além de desempenhar papel positivo na diminuição de peso, pelo fato de aumentar a saciedade, o que conduz a uma menor ingestão calórica, favorecendo o emagrecimento e o controle de peso (OPAS, 2003).

Tais resultados corroboram a pesquisa realizada por Teixeira, Sigulem e Correia (2011), que evidenciaram também a pouca abordagem disponível nos livros didáticos em relação às fibras, uma vez que quase $90 \%$ dos livros analisados não apresentavam alimentos fonte e $78 \%$ não indicavam o consumo diário de água. Em nossa análise, em nenhum momento o livro aborda sobre a importância da ingestão de água (regulação intestinal, desidratação) ou a quantidade diária indicada; apenas registramos uma pequena caixa de texto, na lateral, com o título "Saiba mais", que informa que $75 \%$ do corpo é constituído de água.

A relevância em discutir sobre a análise dos livros didáticos é que esses, em inúmeras situações, são os principais instrumentos que apresentam as informações/conteúdos e direcionam os alunos a estudarem, e, nesse sentido, os livros que não apresentam nenhuma forma de incentivo ao aluno para buscar mais detalhes e novas informações, 
acabam não atendendo à proposta pedagógica. Isto pelo fato de que em diversas instituições os conteúdos abordados pelos professores são trabalhados fielmente, conforme os assuntos contidos no livro adotado (MORAES, 2011).

Embora o livro didático seja uma ferramenta didática muito difundida, é essencial que o professor possa estar atento na escolha desse recurso para verificar se a proposta do livro atende à realidade dos alunos. Além disso, torna-se importante a abordagem que o professor conduzirá para ampliar e facilitar o processo de ensino e de aprendizagem, fazendo com que o aluno se torne ativo e compreenda os conteúdos conforme sua realidade diária (FACCHINI; PAUL, 2014).

Nesse contexto, além de adotar o uso do livro didático, é relevante e faz-se necessário que o professor possa utilizar outros recursos de ensino (internet, revista, vídeos, etc.) que facilitem a compreensão dos alunos, mesmo que esteja trabalhando com um livro de ótima qualidade, bem como possa promover atividades extraclasse a fim de potencializar o processo de ensino e de aprendizagem (DELIZOICOV; ANGOTTI; PERNAMBUCO, 2011). Apesar de possuir um papel de grande relevância, o livro não deve ter uma função centralizadora, pois seu uso apresenta maior potencialidade quando utilizado junto a outros recursos e materiais que ficam a critério do professor (VESTENA; SCREMIN; BASTOS, 2018). Por isso, torna-se importante que o livro apresente conteúdos que possam motivar os alunos a modificarem suas práticas alimentares, conforme observa-se no Quadro 2.

Sobre os conteúdos abordados no livro do oitavo ano, destaca-se a ausência total de esclarecimentos sobre a origem e a causa das doenças destacadas, bem como de uma abordagem relacionada a orientações nutricionais, ou seja, quais os principais cuidados com a patologia e como deve ser realizada sua prevenção no que diz respeito aos hábitos alimentares, além da ausência de conteúdos como o referente aos transtornos alimentares e a influência da mídia no contexto alimentar. Destacam-se essas ausências como sendo um ponto, particularmente, negativo, posto que, na atualidade, é inegável a difusão de como esses assuntos são evidentes em pesquisas, revistas, jornais e na mídia.

Diante desse panorama, tanto a escola quanto os professores assumem uma função importante em relação a proporcionar aos estudantes aulas que contribuam para a formação desses como cidadãos, de forma que possam ser críticos e reflexivos no ambiente em que vivem.

Considerando que o livro influencia de modo decisivo no desenvolvimento dos temas relacionados à promoção da saúde em sala de aula e, consequentemente, na maneira pela qual os alunos e professores conscientizam-se sobre as questões referentes à saúde (ILHA et al., 2013), esse acaba por não atender ao objetivo a que se propõe, que é facilitar o desenvolvimento curricular.

Freitas e Martins (2008), após realizarem um estudo sobre as concepções de saúde no livro de Ciências, afirmam que a promoção da saúde está associada à diminuição dos riscos para a saúde. Para tanto, é preciso que o aluno seja direcionado e instruído a evitar atitudes que possam torná-lo propenso ou acometido com tais problemas. 
Os livros de Ciências têm uma função que os difere dos demais - a aplicação do método científico, estimulando a análise de fenômenos, o teste de hipóteses e a formulação de conclusões. Adicionalmente, o livro de Ciências deve propiciar ao aluno uma compreensão científica, filosófica e estética de sua realidade, oferecendo suporte no processo de formação dos indivíduos/cidadãos. Consequentemente, deve ser um instrumento capaz de promover a reflexão sobre os múltiplos aspectos da realidade e a capacidade investigativa do aluno para que ele assuma a condição de agente na construção do seu conhecimento (VASCONCELOS; SOUTO, 2003. p. 93-94).

No estudo realizado por llha et al. (2013), os autores observaram que a abordagem dada no livro apenas priorizou a descrição das doenças e pequenos informes, dentro do texto, sobre a importância ou como preveni-las. Tal resultado corrobora nossos achados, porém, em nossa análise, os conteúdos foram apenas citados, não sendo identificada nenhuma abordagem relacionada a maiores detalhes das doenças. Concorda-se com llha et al. (2013) quando esses afirmam sobre a importância de promover, para os alunos, atividades que os façam não apenas conhecerem as doenças, mas refletirem sobre a qualidade de vida tanto individual quanto coletiva para gerar mudança de comportamento.

Martins e Castro (2009) também observaram em seu estudo sobre um livro didático de biologia largamente utilizado no Ensino Médio, que tal livro não contribuiu de modo considerável com a formação para a cidadania, pois, segundo os autores, não instiga o desenvolvimento da autonomia dos alunos.

No que diz respeito aos exercícios e atividades analisados, identificou-se que o livro apresenta proposta de atividades, mediante exercícios, contendo perguntas sobre o que foi aprendido nos 10 temas que fazem parte do capítulo 6. São apenas 16 questões. No decorrer dos temas apresentados o livro traz atividades assim intituladas: "Saiba mais" (informações pontuais sobre um assunto); "Entrando na rede" (endereço da internet com mais informações sobre o assunto); "De olho no tema" (atividades que podem ser em grupo, ou não, para serem registradas no caderno); "Descubra” (proposta de atividades práticas para os alunos realizarem e registrarem o que observaram). "Compreender um texto" (obter informações, interpretar, pesquisar e refletir); "Por uma nova atitude" (explorar o problema, analisar o problema e tomar uma decisão); "Explore" (texto, identificar, interpretar e argumentar).

Nesse sentido, fica evidente que o livro analisado apresenta uma série de atividades que podem promover o estímulo ao aluno em buscar mais informações e refletir sobre o tema, embora, em alguns momentos, não sejam trabalhados textos que abranjam conceitos que são pertinentes à realidade dos alunos. Nessa perspectiva, não possibilitam uma possível mudança de hábito, servindo apenas para informação, ou seja, mesmo estando evidente a presença dos temas, exercícios e atividades em diversos momentos, não há uma relação contextualizada, principalmente com assuntos discutidos na contemporaneidade.

De acordo com a análise realizada por llha et al. (2013), também com livros do oitavo ano, os resultados, de certo modo, assemelham-se à nossa análise, pois, segundo os autores, embora o volume do oitavo ano apresente informações pertinentes à te- 
mática da alimentação, o livro não sugere textos ou atividades que provoquem o reconhecimento do cotidiano alimentar dos alunos, o que está adequado às modificações/ substituições necessárias e às deficiências observadas. Isso foi percebido no estudo realizado por Freitas e Martins (2008) que, ao analisarem livros de Ciências do segundo ciclo do Ensino Fundamental (6 a 9o ano), observaram textos que se detêm apenas a informar funções dos alimentos, constituição, origem de doenças e sua relação com carências, não sendo identificados textos que abordem, por exemplo, hábitos culturais, preferências alimentares e condições socioeconômicas.

Nessa perspectiva, concordamos com Freitas e Martins (2008), pois não observamos, ao longo da análise, nenhuma evidência que aborde assuntos relacionados à diversidade e cultura alimentar ou conteúdo relacionado. Essa circunstância chama nossa atenção pelo fato de que, ao se tratar de práticas alimentares saudáveis, deve-se ressaltar a relevância da busca por hábitos alimentares regionais, que são pertinentes ao consumo de alimentos presentes nos distintos locais e apresentam grande valor cultural. Inclusive o próprio guia alimentar para a população brasileira traz, em sua versão mais atual, um capítulo exclusivo para abordar esta temática (BRASIL, 2014).

Além disso, como o livro didático faz parte do contexto escolar, ressalta-se que o Programa Nacional de Alimentação Escolar (PNAE) abrange, em suas diretrizes, o emprego da alimentação adequada e saudável na escola, incluindo o uso de alimentos variados e seguros para compor o cardápio da merenda escolar e que respeitem a cultura e as tradições alimentares, contribuindo para o resgate e a tradição cultural da região e das populações (CHAVES et al., 2007).

Também não foram identificados os assuntos relacionados à alimentação e à influência da mídia nesse contexto, uma vez que a intensa exposição à publicidade de alimentos não saudáveis, veiculados por meio da mídia, é fator que, de fato, compromete o consumo alimentar da população, principalmente de crianças e adolescentes. É necessário ficar atento para a intensa publicização de gêneros alimentícios, pois os anúncios exibidos nos meios midiáticos diferenciam-se de acordo com o público-alvo, ou seja, eles moldam-se em conformidade com a população que quer atingir, a exemplo das diversas estratégias, como a utilização de brinquedos, personagens infantis e brindes voltados ao público infantil e o uso do preço, sabor e tamanho para o público mais adulto, no intuito de alcançar o maior número de indivíduos. Dessa forma, esse meio acaba favorecendo, de certo modo, para a disseminação de hábitos alimentares inadequados para os jovens (BERNHARDT et al., 2013; LIPSKY; IANNOTTI, 2012).

Em 2007 a Organização Mundial da Saúde, juntamente a Sociedade Brasileira de Pediatria, publicou um documento, referente às propagandas de alimentos industrializados, a respeito do marketing de produtos alimentícios ricos em gorduras, açúcar e sal e baixo valor nutricional, estabelecendo regras que tratassem, de modo cauteloso, o que está sendo repassado para as crianças e jovens por meio da mídia (HAWKES, 2007).

No Brasil, apesar dos inúmeros esforços dos profissionais da saúde para impedir o marketing de anúncios de alimentos industrializados com apelo infantil, observa-se que ainda há divulgação de produtos não recomendados e prejudiciais à saúde. Por isso, o trabalho de conscientização sobre a importância da adoção de hábitos de vida saudável e de uma alimentação que promova o crescimento e o desenvol- 
vimento das crianças, bem como a promoção da saúde são necessários. Por ser a escola uma extensão da família, deve contribuir com a formação integral dos indivíduos e junto com os pais promover ações que favoreçam um estilo de vida que vá ao encontro das recomendações nacionais e internacionais para a prevenção de doenças (PRODANOV; CIMADON, 2016, p. 10).

Mais uma vez é importante o papel que a escola exerce no sentido de promover ações de educação alimentar e nutricional, visando a esclarecer, abordar, construir e fazer com que o aluno reflita sobre os fatos e tenha uma criticidade, principalmente sobre o que é imposto de forma tão avassaladora quanto os meios midiáticos o fazem. É fundamental destacar, nesse sentido, que o guia alimentar (BRASIL, 2014) mostra o que se pode fazer para diminuir a relação das crianças com as propagandas, e, entre tais ações, além de alertarem os pais a estarem mais atentos ao que os seus filhos assistem, os estimula a reduzir o tempo destinado à televisão. Além disso, o guia sugere que os pais também entrem em contato com a escola para que o ambiente escolar seja livre de propaganda de produtos industrializados e que seja incorporado no currículo escolar debates/discussões referentes ao papel da publicidade, a fim de tornar os alunos aptos a entenderem o real objetivo da mídia.

Seguindo essa lógica, a criação de programas educacionais torna-se uma das maneiras de desenvolver, aprimorar e difundir o conhecimento das crianças sobre nutrição e saúde, na intenção de promover a formação de bons hábitos alimentares, prevenir doenças relacionadas à má alimentação e garantir a qualidade de vida (FREITAS; COELHO, 2009; CARVALHO; OLIVEIRA; SANTOS, 2010).

\section{CONCLUSÃO}

A partir da análise realizada e da observação dos resultados, foi possível concluir que, embora o livro didático seja, de fato, uma das mais relevantes fontes de informação, sendo, em inúmeros casos, o principal ou único meio de conhecimento científico para os alunos, a abordagem apresentada nos livros didáticos do Ensino Fundamental, analisados neste estudo, é insatisfatória em diversos momentos, exposta de forma superficial e não trazendo aspectos essenciais à temática da Alimentação e Nutrição.

Além do mais, destaca-se que os livros não abrangem os conteúdos de modo a envolver os alunos com situações que possam fazê-los compreender os assuntos apresentados de forma a aprender não apenas conteúdos, mas, sim, para que possam utilizar o conhecimento em âmbito pessoal, individual e coletivo, com o intuito de promover um melhor processo de ensino e de aprendizagem junto a realidade vivenciada, tornando-os cidadãos com formação e visão crítica do mundo.

Dessa maneira, torna-se interessante a introdução de outros assuntos (a exemplo de temas que possam abordar a diversidade alimentar, a cultura alimentar, a transição nutricional, a produção de alimentos, a tecnologia e a importância da mídia no consumo alimentar), a inserção de informações atualizadas (a pirâmide alimentar, a classificação de alimentos de acordo com o atual guia alimentar, os aspectos e riscos da alimentação inadequada, transgênicos e o uso de agrotóxicos), o aprofundamento dos conteúdos 
existentes, bem como uma dinâmica mais atrativa, utilizando diversos recursos didáticos para melhor compreensão dos assuntos ministrados (relacionando o conteúdo de modo contextualizado à rotina diária vivenciada pelos alunos).

É interessante reforçar a importância da inserção da educação nutricional no currículo escolar e da revisão dos conteúdos contidos nos livros didáticos, posto que a inclusão da educação em saúde em sala de aula reforça a aprendizagem para a vida em coletividade e repercute na formação de hábitos que colaboram para a promoção de saúde.

Além disso, são importantes a atenção e a criticidade dos professores em relação aos livros adotados pela escola, a fim de não se deterem, de modo exclusivo, ao uso desse recurso pedagógico, mas, sim, utilizando-o para auxiliar, buscando outros recursos que proporcionem maior amplitude do que for trabalhado/discutido em sala de aula, tornando o aluno mais participativo no contexto abordado.

Mediante os resultados alcançados, preconiza-se que o livro de Ciências possa apresentar uma abordagem mais direcionada à visão nutricional, buscando enfatizar as práticas da educação nutricional e um maior diálogo entre as questões relacionadas à saúde e alimentação, não apenas com a visão conteudista, mas como perspectiva de ampliar a compreensão dos estudantes e professores que o utilizam sobre Alimentação e Nutrição.

\section{REFERÊNCIAS}

BARATA, I. M. S.; BARRETO, M. M. O tema alimentação no ensino de ciências - análise de livros didáticos para os anos finais do Ensino Fundamental. 2013. 18 f. Trabalho (Conclusão de Curso de Graduação em Ciências Biológicas,) - Faculdade de Ciências da Educação e Saúde - Faces, Brasília, 2013.

BERNHARDT, A. M. et al. How Television Fast Food Marketing Aimed at Children Compares with Adult Advertisements. PLoS One, 8(8), 2013. DOI: 10.1371/journal.pone.0072479.

BIZZO, M. L. G.; LEDER, L. Educação nutricional nos Parâmetros Curriculares Nacionais para o Ensino Fundamental. Revista Nutrição, Campinas, v. 18, n. 5, p. 661-67, 2005.

BOOG, M. C. F. Educação nutricional: passado, presente, futuro. Revista Nutrição, Campinas, v. 10, n. 1, p. 5-19, 1997.

BRASIL. Parâmetros Curriculares Nacionais: terceiro e quarto ciclos do Ensino Fundamental (PCN). Brasília: MEC - Secretaria de Educação Fundamental, 1998a.

BRASIL. Ministério da Educação. Conselho Nacional de Educação. Parecer CNE/CEB n. 4/98, de 29 de janeiro de 1998. Institui as Diretrizes Curriculares Nacionais para o Ensino Fundamental. Diário Oficial da União. Brasília, DF, 30 jan. 1998b.

BRASIL. Ministério da Educação. Guia de livros didáticos. Brasília: Ministério da Educação, 2003.

BRASIL. Ministério da Saúde. Secretaria de Atenção à Saúde. Departamento de Atenção Básica. Guia alimentar para a população brasileira. 2. ed. Brasília, DF, 2014.

CARDOSO, R. A. de C.; MOREIRA, M. C. do A. O tema alimentação em livros didáticos de ciências. Ciência em Tela, v. 9, n. 1, p. 1-9, 2016.

CARVALHO, A. P.; OLIVEIRA, V. B.; SANTOS, L. C. Hábitos alimentares e práticas de educação nutricional: atenção a crianças de uma escola municipal de Belo Horizonte, Minas Gerais. Pediatria, São Paulo, 32(1), p. 20-27, 2010.

CATRIB, A. M. F. et al. Saúde no espaço escolar. In: BARROSO, M. G. T.; VIEIRA, N. F. C.; VARELA, Z. M. V. (org.). Educação em saúde no contexto da promoção humana. Fortaleza: Edições Demócrito Rocha, 2003. CHAVES, L. G. et al. Programa nacional de alimentação escolar - compromisso com a saúde pública. Revista Nutrição Profissional, São Paulo, v. 1, n. 22, 2007.

DELIZOICOV, D.; ANGOTTI, J. A.; PERNAMBUCO, M. M. Ensino de Ciências: fundamentos e métodos. 4. ed. São Paulo: Cortez, 2011. 
FACCHINI, J. M.; PAUL, A. Avaliação de livros didáticos como ferramenta para o ensino de educação ambiental nos 6으 e 7음 anos do Ensino Fundamental. Ágora: Revista de Divulgação Científica, v. 19, n. 2, p. 83-99, jul./dez. 2014.

FREITAS, A. S. S.; COELHO, S. C.; RIBEIRO, R. L. Obesidade infantil: influência de hábitos alimentares inadequados. Saúde \& Amb. Rev., 4(2), p. 9-14, 2009.

FREITAS, E. O. de; MARTINS, I. Concepções de saúde no livro didático de ciências. Revista Ensaio Pesquisa em Educação em Ciências, v. 10, n. 2, 2008.

HAAS, P.; ANTON, A.; FRANCISCO, A. de. Câncer colo retal no Brasil: consumo de grãos integrais como prevenção. RBAC, Santa Catarina, v. 39, n. 3, p. 231-235, 2007.

HAWKES, C. Marketing Food to Children: Changes in the Global Regulatory Environment 2004-2006. International Food Policy Research Institute, 2007. ISBN: 9241591579. 96 p.

ILHA, P. V. et al. A promoção da saúde nos livros didáticos de ciências do 6으 ao 9ano. Alexandria - Revista de Educação em Ciência e Tecnologia, Florianópolis, v. 6, n. 3, p. 107-120, 2013.

IPIRANGA, L. Prefácio. In: LEME, M. J. P.; PERIN, M. L. F. 1, 2...Feijão com arroz: educação alimentar. Brasília: FAE; MEC, 1995. 1995. V. 1.

LIPSKY, L. M.; IANNOTTI, R. J. Associations of television viewing with eating behaviors in the 2009 Health Behaviour in School-aged Children Study. Arch Pediatr Adolesc Med., 166(5), p. 465-472, 2012.

MACHADO, V. M.; DE CARVALHO, D. S. Elaboração de uma sequência didática sobre hábitos alimentares e nutricionais saudáveis como contribuição para as aulas de ciências no ensino fundamental. Interfaces da Educação, Paranaíba, v. 6, n. 17, p. 188-205, 2015.

MARTINS, L.; CASTRO, T. de A. Abordagem de saúde em um livro didático de biologia largamente utilizado no ensino médio brasileiro. In: ENCONTRO NACIONAL DE PESQUISA EM EDUCAÇÃO EM CIÊNCIAS, 7., 2009. Florianópolis. Anais [...]. Florianópolis: Enpec, 2009.

MORAES, J. U. P. O livro didático de física e o ensino de física: suas relações e origens. Scientia Plena, v. 7, n. 9, p. 1-4, 2011.

OPAS. Organização Pan-Americana da Saúde. CARMEN - Iniciativa para Conjunto de Ações para Redução Multifatorial de Enfermidades Não Transmissíveis. Brasil, 2003.

PERES, C. et al. Percepção de estudantes sobre saúde, alimentação e atividade física após intervenção com a metodologia da problematização. Revista Contexto \& Educação, 33(104), p. 346-364, 2018.

PICCOLI, L.; JOHANN, R.; CORRÊA, E. N. A educação nutricional nas séries iniciais de escolas públicas estaduais de dois municípios do oeste de Santa Catarina. Nutrire: Rev. Soc. Bras. Alim. Nutr. = J. Brazilian Soc. Food Nutr., São Paulo, SP, v. 35, n. 3, p. 1-15, dez. 2010.

PIPITONE, M. A. P.; SILVA, M. V.; STURION, G. L.; CAROBA, D. C. R. A. Educação nutricional no programa de ciências para o ensino fundamental. Saúde em Revista, Piracicaba, v. 5, n. 9, p. 29-37, 2003.

PRODANOV, S. S.; CIMADON, H. M. S. A influência da publicidade nos hábitos alimentares de crianças em idade escolar. Conhecimento on-line, Novo Hamburgo, v. 1, p. 3-12, ago. 2016.

REBOUÇAS, T. B. P. Análise dos conteúdos de alimentação e nutrição em livros didáticos do Ensino Fundamental do Distrito Federal. 2013. 40 f. Trabalho (Conclusão de Curso de Graduação de Nutrição) - Universidade de Brasília, 2013.

RIQUE, A. B. R.; SOARES, E. de A.; MEIRELLES, C. de M. Nutrição e exercício na prevenção e controle das doenças cardiovasculares. Rev. Bras. Med. Esporte, Niterói, v. 8, n. 6, p. 244-254, 2002.

SANTOS, L. A. S. Educação alimentar e nutricional no contexto da promoção de práticas alimentares saudáveis. Rev. Nutr., Campinas, v. 18, n. 5, p. 681-692, set./out. 2005.

SCHMITZ, B. A. S., RECINE, E., CARDOSO, G. T., SILVA, J. R. M., AMORIM, N. F. A., BERNARDON, R., RODRIGUES, M. L. C. F. A escola promovendo hábitos alimentares saudáveis: uma proposta metodológica de capacitação para educadores e donos de cantina escolar. Cad. Saúde Pública, 24 (2), 312-322, 2008.

TEIXEIRA, T. C.; SIGULEM, D. M.; CORREIA, I. C. Avaliação dos conteúdos relacionados à nutrição contidos nos livros didáticos de biologia do ensino médio. Rev. Paul. Pediatr., 29 (4), p. 560-566, 2011.

VASCONCELOS, S. D.; SOUTO, E. O livro didático de ciências no Ensino Fundamental - Proposta de critérios para análise do conteúdo zoológico. Ciência \& Educação, v. 9, n. 1, p. 93-104, 2003.

VESTENA, R.; SCREMIN, G.; BASTOS, G. Alimentação Saudável: contribuições de uma sequência didática interativa para o ensino de ciências nos anos iniciais. Revista Contexto \& Educação, ljuí: Editora Unijuí, v. 33, n. 104, p. 365-394, 2018. 